Relations between the aromaticity and magnetic dipole transitions in the electronic spectra of hetero[8]circulenes

\author{
Valiev, R. R.
}

2018-12-28

Valiev , R R , Baryshnikov , G V \& Sundholm , D 2018 , ' Relations between the aromaticity and magnetic dipole transitions in the electronic spectra of hetero[8]circulenes ' , Physical Chemistry Chemical Physics, vol. 20 , no. 48 , pp. 30239-30246 . https://doi.org/10.1039/c8cp05694c

http://hdl.handle.net/10138/309475

https://doi.org/10.1039/c8cp05694c

unspecified

acceptedVersion

Downloaded from Helda, University of Helsinki institutional repository.

This is an electronic reprint of the original article.

This reprint may differ from the original in pagination and typographic detail.

Please cite the original version. 


\title{
Relations between the aromaticity and magnetic dipole transitions in the electronic spectra of hetero[8]circulenes
}

\author{
R. R. Valiev ${ }^{\mathrm{a}, \mathrm{b} *}$, G. V. Baryshnkiov,c, D. Sundholm ${ }^{\mathrm{b}}$ \\ ${ }^{a}$ Tomsk State University, 36 Lenin Avenue, 634050, Tomsk, Russian Federation, \\ E-mail: valievrashid@gmail.com \\ ${ }^{b}$ Department of Chemistry, University of Helsinki, P.O. Box 55 (A.I. Virtanens plats 1), \\ Helsinki FIN-00014, Finland \\ ${ }^{c}$ Division of Theoretical Chemistry and Biology, School of Engineering Sciences in Chemistry, \\ Biotechnology and Health, KTH Royal Institute of Technology, 10691 Stockholm, Sweden
}

\begin{abstract}
Magnetically induced current densities have been calculated at the second-order Møller-Plesset perturbation theory (MP2) level for seven hetero[8]circulenes and their dicationic and dianionic forms. Calculations of the magnetic dipole transition moments have also been carried out at the algebraic diagrammatic construction (ADC(2)) and the second-order approximate coupled-cluster (CC2) levels. The calculations show that the degree of aromaticity and the size of the magnetic dipole transition moment of the lowest magnetic-dipole allowed excited state are related. We show that neutral hetero[8]circulenes are weakly antiaromatic when the first excited state with a large magnetic dipole transition moment of 10-16 a.u. lies at high energies ( 2.8-3.5 eV). For the dications, this transition often lies at much lower energies. Hetero[8]circulene dications with large magnetic dipole transition moments are strongly antiaromatic. The lowest excited states of the hetero[8]circulene dianions have very small magnetic dipole transition moments implying that they are aromatic.
\end{abstract}




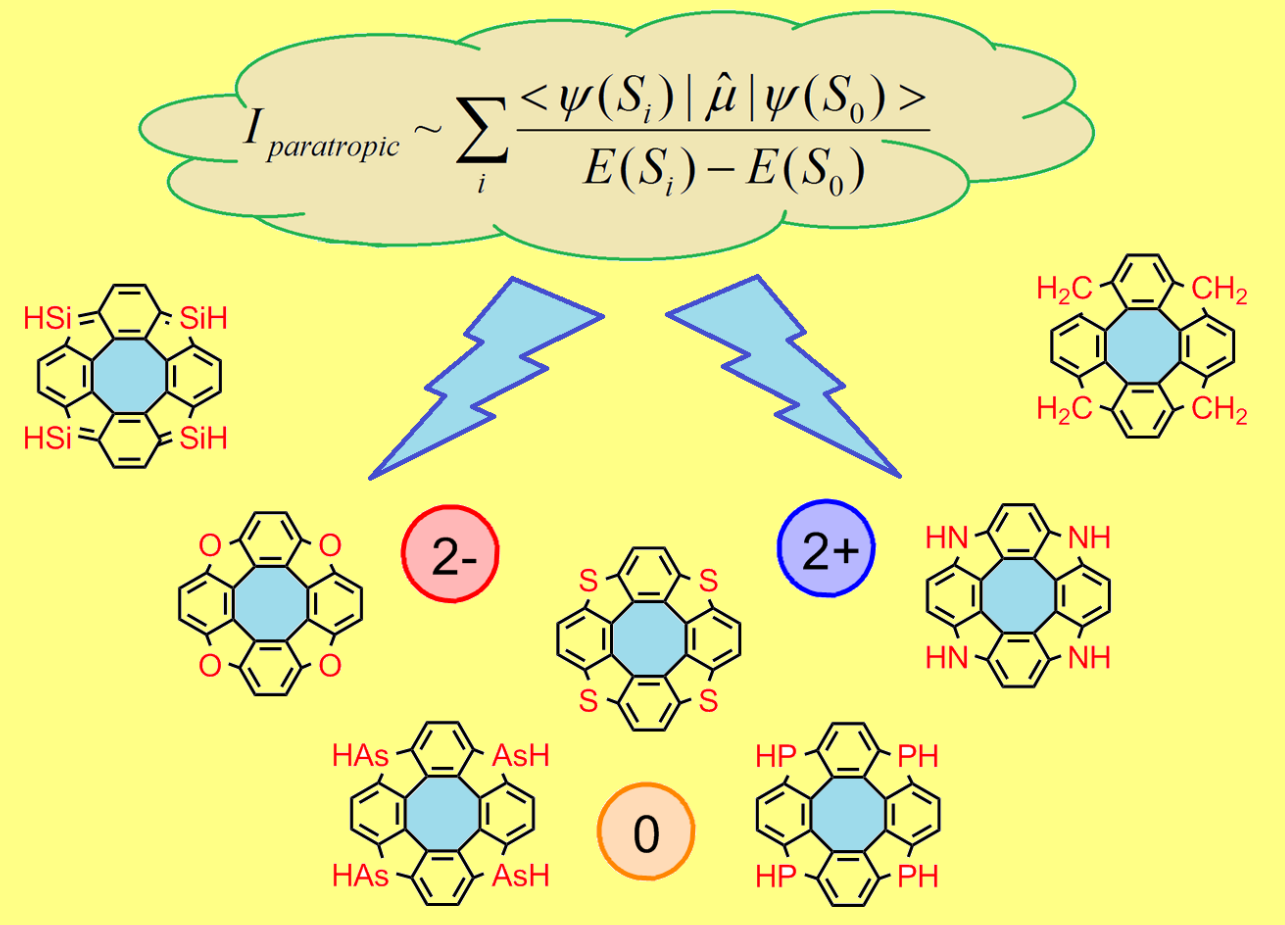

Graphical abstract 


\section{INTRODUCTION}

The hetero[8]circulenes constitute a group of macroheterocyclic compounds that are characterized by unique spectral properties because of their peculiar electronic structure [1-3]. They can be used in nanophotonic applications [4], in photodynamic therapy [5], as the active media in the fabrication of organic light-emitting diodes (OLEDs) [6-8], and in organic field-effect transistors (OFETs) [9-11]. The generic molecular structure of the studied hetero[8]circulenes are shown in

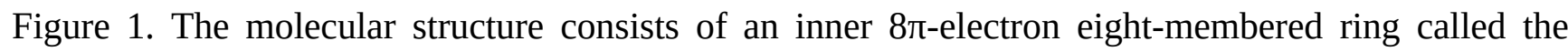

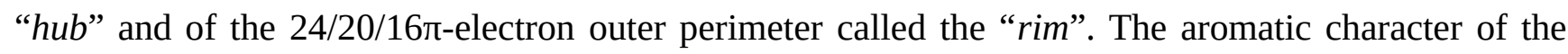
hetero[8]circulenes based on structural and magnetic ring-current criteria has been thoroughly investigated in our previous works [12-15], which showed that neutral hetero[8]circulenes do not sustain any net ring-current and can therefore be considered nonaromatic. Even though hetero[8]circulenes sustain strong currents, the net ring-current strength vanishes, because the magnetically induced ring current in the rim is diatropic and the ring current in the hub is of the same strength but flows in the opposite e.g., in the paratropic direction [12-15].

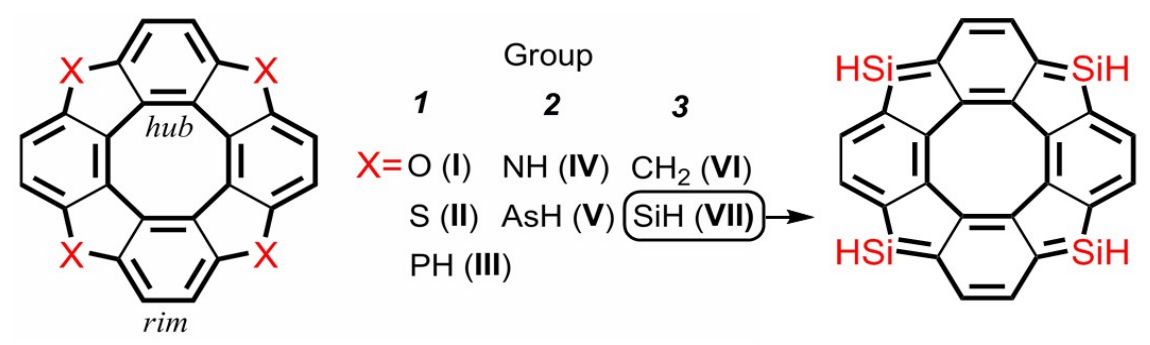

Figure 1. The molecular structure of the studied hetero[8]circulenes can be grouped into the three classes based on the aromatic properties of the neutral molecule and doubly charged ions. For the SiH-containing compound, the single-double bond alternation differs from the other studied molecules as shown in the left part.

Radenkovic et. al. [16] draw similar conclusions for a series of benzoannelated tetraoxa[8]circulenes based on calculations using the continuous transformation of origin of current density diamagnetic zero (CTOCD-DZ) method [17]. The obtained ring current maps showed that there are two weakly interacting current flows, namely a diatropic ring current around the rim and a paratropic ring current around the inner hub of the cyclooctatetraene core [16]. The results do not support the so-called

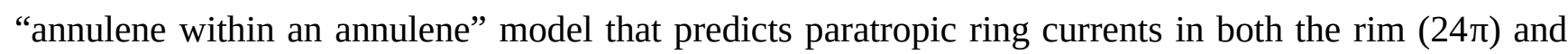

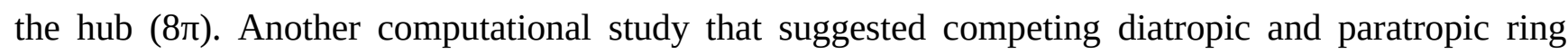
currents in the rim and the hub for a number of selected tetraoxa[8]circulenes was reported by Kleinpeter et. al. [18]. Their conclusions were based on through space NMR shielding (TSNMRS) calculations, which were visualized using iso-chemical-shielding-surfaces (ICSS) [19]. Nucleusindependent chemical shifts (NICS) calculations [20] for the individual rings of the tetraoxa[8]circulene molecule and related isoelectronic hetero[8]circulenes are also able to identify the 
inner COT ring as an antiaromatic moiety, whereas the five- and six-membered rings was shown to have aromatic character [1, 3, 21, 22]. However, NICS calculations cannot be used for estimating the balance between the global paratropic and diatropic magnetically-induced ring currents of the rim and the hub, whereas current density calculations using the gauge-including magnetically induced currents (GIMIC) and CTOCD-DZ methods yield explicit information about the current density flow of the molecules.

The doubly charged hetero[8]circulenes have interesting aromatic properties [13-15]. It has been shown that the dications of tetrathia[8]circulene (I), tetraoxa[8]circulene (II) and tetraphospha[8]circulene (III) are strongly antiaromatic, whereas their dianions are aromatic [12-15]. The calculated degree of aromaticity of strongly antiaromatic molecules depends to some extent on the employed computational level. B3LYP calculations tend to overestimate the antiaromatic character of strongly antiaromatic molecules. It is therefore necessary to study the current densities using ab initio correlated levels of theory such as second-order Møller-Plesset perturbation theory (MP2) level or alternatively to employ a functional with a large fraction of Hartree-Fock exchange [23-25].

The reason for the strong antiaromaticity of porphyrinoids like carbaporphyrins, carbathiaporphyrins, isophlorins and expanded porphyrins has been shown to be due to a low-lying excited state that has a large magnetic dipole transition moment from the ground state [23-25]. The paratropic ring current of strongly antiaromatic porphyrinoids can result in closed-shell paramagnetic molecules [23]. Thus, antiaromatic hetero[8]circulenes sustaining strong paratropic ring currents might also be paramagnetic. In this work, we study at correlated $a b$ initio levels of theory the molecular aromaticity and ground-state transition properties of the lowest excited states of selected neutral and doubly charged hetero[8]circulenes.

\section{INVESTIGATED MOLECULES}

Three groups of hetero[8]circulenes with the different aromatic character have been studied. The first group consists of tetraoxa[8]circulene (I), tetrathia[8]circulene (II) and tetraphospha[8]circulene (III), which have similar aromatic properties. Their neutral form is weakly antiaromatic, the dications are strongly antiaromatic and the dianions are aromatic [13-15]. Tetraaza[8]circulene (IV) and tetraarsena[8]circulene $(\mathbf{V})$ are the second group. The neutral form is weakly antiaromatic, the dication is nonaromatic or very weakly antiaromatic, and the dianion is aromatic [13-15]. The hetero[8]circulenes species belonging to the groups 1 and 2 have $8 \pi$ electrons in the hub and $24 \pi$ electrons in the rim. The third group consists of tetramethylenephenylene (VI), which has $8 \pi$ electrons in the hub and $16 \pi$ electrons in the rim, and tetrasila[8]circulene (VII) with $8 \pi$ electrons in the hub and $20 \pi$ electrons in the rim. The neutral VI and VII are weakly antiaromatic, whereas the dication and 
the dianion are aromatic [13-15]. The molecular structures of the studied hetero[8]circulenes are shown in Figures 2.

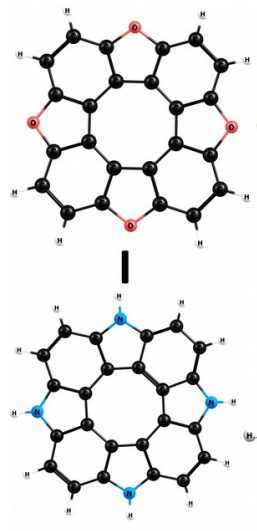

IV

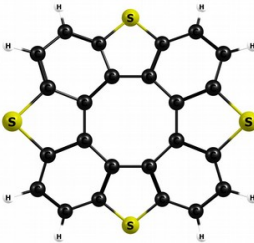

II

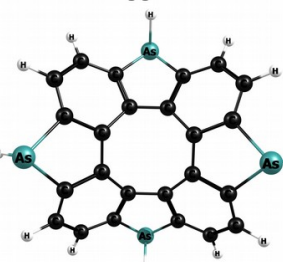

V

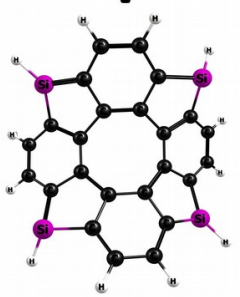

VII

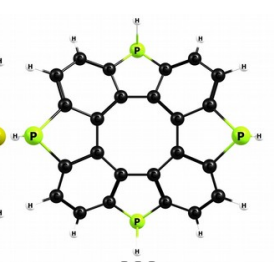

III

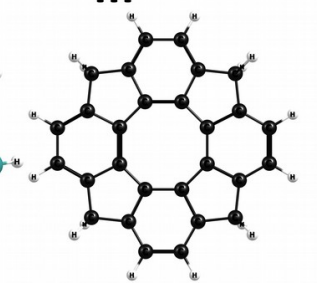

VI

Figure 2. The molecular structure of the studied hetero[8]circulenes optimized at the B3LYP/def2-TZVP level. I - tetrathia[8]circulene, II - tetraoxa[8]circulene, III - tetraphospha[8]circulene, IV tetraaza[8]circulene, $\quad$ V - tetraarsena[8]circulene, VI - tetramethylenephenylene and VII tetrasila[8]circulene.

\section{COMPUTATIONAL METHODS}

The ground-state molecular structure of the neutral I-VII as well as of the doubly charged cations and anions of I-VII were optimized at the density functional theory (DFT) [26] level using the B3LYP functional [27,28] and the def2-TZVP basis set [29]. The vertical excitation energies (VEE) and the electronic magnetic-dipole transition moments $(\boldsymbol{m})$ were calculated at the algebraic diagrammatic construction model through second order (ADC(2)) [30,31]. Approximate second-order coupled-cluster calculations (CC2) [32] were used for assessing the accuracy of the ADC(2) results for the strongly antiaromatic dications of I-III. We calculated the VEEs and transition moments at the $a b$ initio correlated levels, because time-dependent density functional theory (TDDFT) calculations often yield inaccurate excitation energies for multi-charged species. The calculations were performed with the Turbomole program version 7.2 [33,34]. The multiconfiguration character of the VII molecule was investigated by performing extended multi-configuration quasi-degenerate perturbation theory (XMCQDPT2) [35]. The XMC-QDPT2 calculations were performed using the firefly software [36]. The excitation energies of the first singlet and triplet states were calculated at the XMC-QDPT2 level for 
the VII molecule, which has a low-lying excited singlet state with an excitation energy of $0.21 \mathrm{eV}$ at the ADC(2) level. The active space of the complete active space self-consistent field (CASSCF) calculations needed for the XMC-QDPT2 study consisted of 10 electrons in 10 orbitals. State averaging was performed for the four lowest states. The effective Hamiltonian contained 35 states.

Magnetically induced current densities (current strengths) were calculated using GIMIC software [37-41] at the second-order Møller-Plesset perturbation theory (MP2) level [42]. GIMIC uses basis-set information and density matrices that are obtained when calculating nuclear magnetic resonance (NMR) shielding constants [37-41]. The NMR shielding calculations were performed at the MP2 level using Turbomole 7.2 [30, 33, 34]. Ring-current strengths ( $I$ in nA/T) and current strengths passing selected chemical bonds were obtained by integrating the current density that flows through planes intersecting the chemical bonds $[38,41]$. The integrated ring-current strengths can be used as an aromaticity index, since the ring-current (susceptibility) strength for benzene is $11.8 \mathrm{nA} / \mathrm{T}$ and for the antiaromatic cyclobutadiene it is $-19.8 \mathrm{nA} / \mathrm{T}$. Nonaromatic molecules have very small net ring-current strengths [37]. The aromatic pathways of the multiring molecules such as hetero[8]circulenes and porphyrinoids can be determined by calculating the current strengths that pass selected chemical bonds [12-15, 25, 37].

\section{RESULTS AND DISCUSSIONS}

\subsection{Current strengths}

Ring-current strength calculations at the B3LYP level lead to an overestimation of the paratropic current density contribution of strongly antiaromatic porphyrinoids, whereas MP2 calculations yielded more accurate magnetically induced current density (MIC) strengths [23-25]. Thus, $a b$ initio correlated calculations at least at the MP2 level are needed in order to obtain reliable MIC strengths for strongly antiaromatic hetero[8]circulenes.

MIC strengths calculated at the MP2 level of theory are almost the same as those previously obtained in DFT calculations using the B3LYP functional for most of the studied hetero[8]circulenes. The discrepancies between the MIC strengths calculated at the MP2 and DFT levels are generally less than $0.5 \mathrm{nA} / \mathrm{T}$. The exceptions are the dications of (I-III) ${ }^{2+}$ and the neutral form of VII. The currentdensity strengths and current pathways of the hetero[8]circulenes are therefore investigated at the MP2 level in this work. The molecular structures and current pathways are shown in Figure 3. The current density of the rest of the hetero[8]circulenes has been discussed in detail in previous studies [13-15].

The net ring-current strength of the antiaromatic $\mathbf{I}^{2+}, \mathbf{I I}^{2+}, \mathbf{I I I}^{2+}, \mathbf{V I I}^{0}$ species calculated at the MP2 level are $-46,-66,-51$ and $-13.2 \mathrm{nA} / \mathrm{T}$, respectively, which can be compared with the corresponding net ring-current strength of -55, -84, -66 and -22.4 nA/T calculated at the B3LYP level [14]. The differences in the current strengths obtained at the two levels of theory are in the range of 9- 
$18 \mathrm{nA} / \mathrm{T}$. Larger discrepancies were obtained for the very strongly antiaromatic molecules. The calculations show that the two levels of theory yield roughly the same current pathways, whereas the current strengths of the individual bonds calculated at the MP2 level are weaker than the B3LYP currents in about the same proportion as between the net ring-current strengths. The strengths of the current pathways are shown in Figure 3. The main current pathways and the degree of molecular aromaticity are qualitatively the same at the two computational levels.

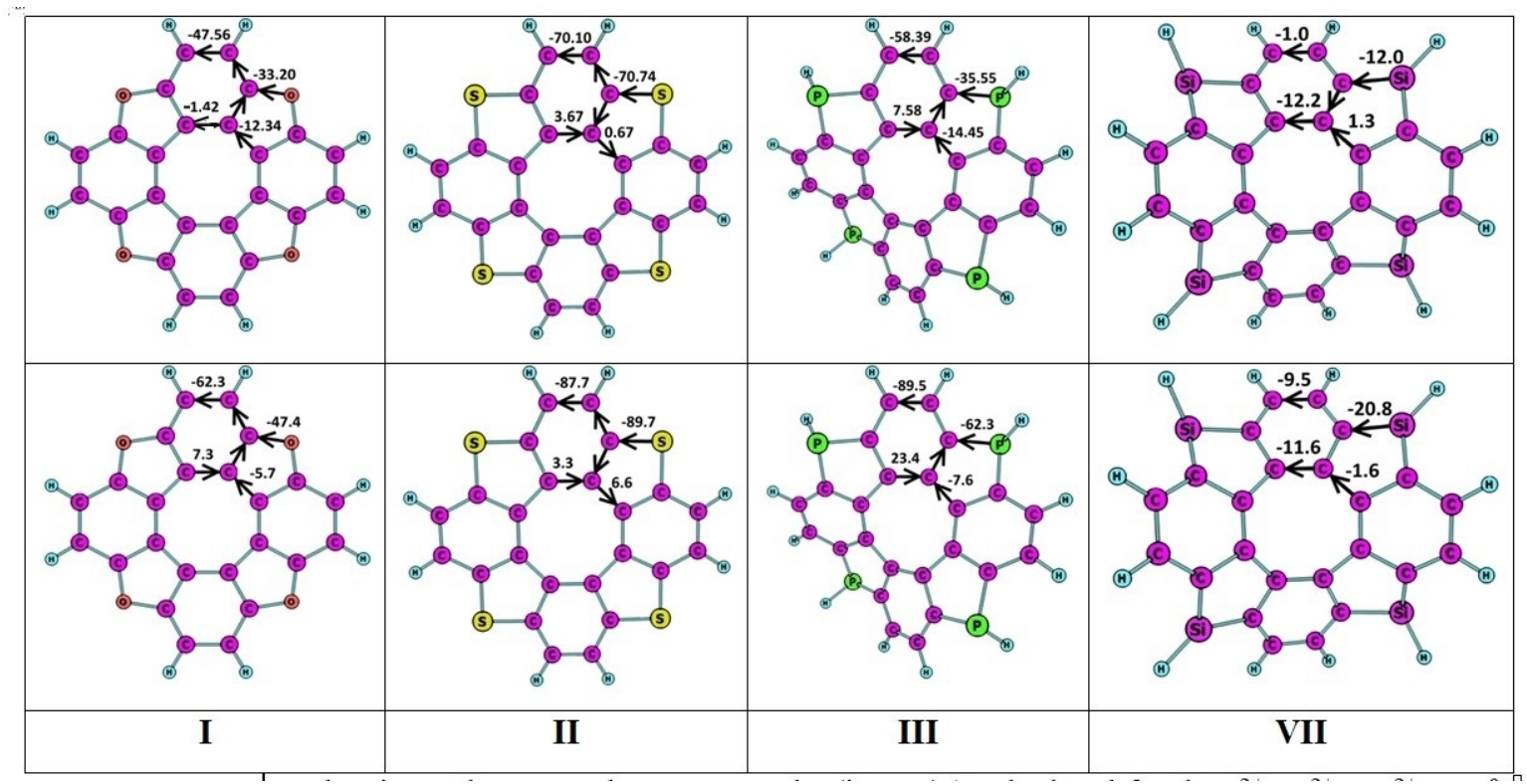

Figure 3. Current density pathways and MIC strengths (in nA/T) calculated for the $\mathbf{I}^{2+}, \mathbf{I I}^{2+}, \mathbf{I I I}^{2+}, \mathbf{V I I}^{0}$ species at the MP2 level (top) and the B3LYP (bottom).

\subsection{Excitation energies and electronic magnetic-dipole transition moments}

\subsubsection{Molecules I, II and III}

The vertical excitation energies (VEE) and magnetic dipole transition moments ( $\boldsymbol{m}$ ) of the electronic transitions calculated at the ADC(2) and CC2 levels for the molecules I-III are summarized in Table 1. The data in Table 1 show that similar VEEs are obtained at the two levels of theory with discrepancies of less than $0.2 \mathrm{eV}$. Almost the same $\boldsymbol{m}$ values are also obtained in the ADC(2) and CC2 calculations. The lowest or the second-lowest excited state of the dication of I-III at $0.44-0.65 \mathrm{eV}$ has a strong magnetic dipole allowed transition from the ground state with an $\boldsymbol{m}$ value of 7-15 a.u. The excitation energy of the corresponding strongly magnetic dipole allowed transition, with $\boldsymbol{m}$ values of 10-14 a.u. for the neutral molecules, is in the range of 3.12-3.67 eV. The dianions of I-III have no strong magnetic dipole allowed transitions among the eight lowest excited states. For the anions, the $\boldsymbol{m}$ values are in the range of 0.0-0.4 a.u. The paratropic contribution to the ring-current strength that is responsible for the molecular antiaromaticity can be estimated using perturbation theory as [38,43,44]: 


$$
I_{\text {paratropic }} \sim \sum_{i} i \psi\left(S_{i}\right)|\hat{L}| \psi\left(S_{0}\right)>\frac{i}{E\left(S_{i}\right)-E\left(S_{0}\right)} i \quad I_{\text {paratropic }} \sim \sum_{i} \frac{<\left(\left(S_{i}\right)|\widehat{L}| \mathrm{c}\left(S_{\mathbf{0}}\right)>\right.}{E\left(S_{i}\right)-E\left(S_{\mathbf{0}}\right)} \text {, }
$$

where $i \psi\left(S_{i}\right)|\hat{L}| \psi\left(S_{0}\right)>i \dot{i}$ is the matrix element of the angular momentum operator for the transition between the $i$-th singlet excited state $\left(S_{i}\right)$ and the electronic ground state $\left(S_{0}\right)$. $E\left(S_{i}\right)-E\left(S_{0}\right)$ is the vertical ground-state excitation energy to the $S_{i}$ state [24]. For the studied closed-shell molecules, the following expression holds:

$$
i \psi\left(S_{i}\right)|\hat{\mu}| \psi\left(S_{0}\right)>=<\psi\left(S_{i}\right)|\hat{L}| \psi\left(S_{0}\right)>i \dot{i}
$$

where $\hat{\mu}$ is the magnetic-dipole operator. Eq. (1) and Eq. (2) show that there is a relation between electronic magnetic dipole transition moments and antiaromatic properties of molecules $[43,44]$. The small excitation energies of 0.44-0.65 eV for $\mathbf{I}^{2+}, \mathbf{I I}^{2+}$, and $\mathbf{I I I}^{2+}$ combined with the large $\boldsymbol{m}$ values of 715 a.u. lead to a dominating paratropic ring-current strength and the obtained antiaromatic character of the molecules. For neutral I-III, the electronic transition still possesses a large $\boldsymbol{m}$ value (Table 1). However, the states are much higher in energy implying that their contribution to the paratropic ring current is smaller than for the dications. The neutral molecules are practically nonaromatic sustaining very weak paratropic ring currents of a few nA/T. The dications $\left(\mathbf{I}^{2+}, \mathbf{I I}^{2+}, \mathbf{I I I}^{2+}\right)$ have several low-lying magnetic-dipole allowed excited states that contribute to the paratropic ring current.

Table 1. Vertical excitation energies (VEE in eV) and the corresponding magnetic dipole transition moments in parenthesis (a.u.) calculated at the ADC(2) and CC2 levels for the neutral and doubly charged I-III species. The VEEs and transition moments of the states with large magnetic dipole transition moments are highlighted. The MIC strengths (in nA/T) calculated at the MP2 level are also

\begin{tabular}{|c|c|c|c|c|c|c|c|}
\hline \multirow{2}{*}{$\frac{\text { Molecule }}{\text { I }}$} & \multirow[b]{2}{*}{ transition } & \multicolumn{2}{|c|}{ Neutral } & \multicolumn{2}{|c|}{ Dication } & \multicolumn{2}{|c|}{ Dianion } \\
\hline & & CC2 & $\operatorname{ADC}(2)$ & CC2 & $\mathrm{ADC}(2)$ & CC2 & $\mathrm{ADC}(2)$ \\
\hline & $\mathrm{S}_{0} \rightarrow \mathrm{S}_{1}$ & 3.46(13.8) & 3.48(12.9) & $0.44(0.0)$ & $0.38(0.00)$ & $2.33(0.0)$ & $2.44(0.00)$ \\
\hline & $\mathrm{S}_{0} \rightarrow \mathrm{S}_{2}$ & $3.64(0.0)$ & $3.67(0.00)$ & $0.65(10.7)$ & 0.53(7.90) & $2.33(0.0)$ & $2.44(0.00)$ \\
\hline & $\mathrm{S}_{0} \rightarrow \mathrm{S}_{3}$ & $3.64(0.0)$ & $3.67(0.00)$ & $0.98(0.0)$ & $0.65(1.10)$ & $2.81(0.0)$ & $3.04(0.00)$ \\
\hline & $\mathrm{S}_{0} \rightarrow \mathrm{S}_{4}$ & $3.75(0.0)$ & $3.72(0.00)$ & $2.14(0.0)$ & $1.87(2.22)$ & $3.33(0.0)$ & $3.26(0.00)$ \\
\hline & $\mathrm{S}_{0} \rightarrow \mathrm{S}_{5}$ & $4.54(0.0)$ & $4.63(0.00)$ & $2.17(0.0)$ & $2.13(0.00)$ & $3.34(0.0)$ & $3.28(0.00)$ \\
\hline & $\mathrm{S}_{0} \rightarrow \mathrm{S}_{6}$ & $4.95(0.0)$ & $5.04(0.00)$ & $2.73(0.40)$ & $2.65(0.00)$ & $3.40(0.0)$ & $3.28(0.00)$ \\
\hline & $\mathrm{S}_{0} \rightarrow \mathrm{S}_{7}$ & $4.95(0.0)$ & $5.35(0.00)$ & $2.82(0.8)$ & $2.75(0.60)$ & $3.34(0.0)$ & $3.28(0.00)$ \\
\hline & $\mathrm{S}_{0} \rightarrow \mathrm{S}_{8}$ & $5.31(0.0)$ & $5.35(0.00)$ & $3.02(9.0)$ & $2.96(7.80)$ & $3.55(0.2)$ & $3.65(0.14)$ \\
\hline & $\begin{array}{c}I(\mathrm{nA} / \mathrm{T}) \\
\mathrm{MP} 2\end{array}$ & \multicolumn{2}{|c|}{-2.5} & \multicolumn{2}{|c|}{-46.1} & \multicolumn{2}{|c|}{22.1} \\
\hline & & \multicolumn{2}{|c|}{ Neutral } & \multicolumn{2}{|c|}{ Dication } & \multicolumn{2}{|c|}{ Dianion } \\
\hline \multirow[t]{2}{*}{ II } & transition & CC2 & $\operatorname{ADC}(2)$ & CC2 & $\operatorname{ADC}(2)$ & CC2 & $\mathrm{ADC}(2)$ \\
\hline & $\mathrm{S}_{0} \rightarrow \mathrm{S}_{1}$ & $3.43(0.0)$ & $3.41(0.0)$ & $0.53(15.0)$ & $0.48(14.6)$ & $1.85(0.0)$ & $1.83(0.0)$ \\
\hline
\end{tabular}
reported. 


\begin{tabular}{|c|c|c|c|c|c|c|c|}
\hline & $\mathrm{S}_{0} \rightarrow \mathrm{S}_{2}$ & $3.43(0.0)$ & $3.43(0.0)$ & $0.60(0.0)$ & $0.51(0.00)$ & $1.95(0.1)$ & $1.92(0.1)$ \\
\hline & $\mathrm{S}_{0} \rightarrow \mathrm{S}_{3}$ & $3.43(0.0)$ & $3.43(0.0)$ & $0.60(0.0)$ & $0.53(0.00)$ & $1.95(0.1)$ & $1.92(0.1)$ \\
\hline & $\mathrm{S}_{0} \rightarrow \mathrm{S}_{4}$ & $3.57(14.4)$ & 3.67(13.4) & $2.14(0.0)$ & $2.04(0.00)$ & $2.10(0.0)$ & $2.15(0.0)$ \\
\hline & $\mathrm{S}_{0} \rightarrow \mathrm{S}_{5}$ & $4.43(0.0)$ & $4.53(0.0)$ & $2.18(0.0)$ & $2.15(0.00)$ & $2.46(0.2)$ & $2.51(0.2)$ \\
\hline & $\mathrm{S}_{0} \rightarrow \mathrm{S}_{6}$ & $4.48(0.0)$ & $4.55(0.00)$ & $2.33(0.00)$ & $2.37(0.00)$ & $2.46(0.2)$ & $2.51(0.2)$ \\
\hline & $\mathrm{S}_{0} \rightarrow \mathrm{S}_{7}$ & $4.78(0.0)$ & $4.55(0.00)$ & $2.55(0.3)$ & $2.49(0.2)$ & $1.85(0.0)$ & $1.87(0.0)$ \\
\hline & $\mathrm{S}_{0} \rightarrow \mathrm{S}_{8}$ & $4.88(0.0)$ & $4.90(0.0)$ & $3.09(10.2)$ & $3.10(10.4)$ & $1.95(0.1)$ & $2.05(0.2)$ \\
\hline & $\begin{array}{c}I(\mathrm{nA} / \mathrm{T}) \\
\mathrm{MP} 2\end{array}$ & \multicolumn{2}{|c|}{-0.03} & \multicolumn{2}{|c|}{-66.0} & \multicolumn{2}{|c|}{20.6} \\
\hline III & & \multicolumn{2}{|c|}{ Neutral } & \multicolumn{2}{|c|}{ Dication } & \multicolumn{2}{|c|}{ Dianion } \\
\hline & & CC2 & $\operatorname{ADC}(2)$ & CC2 & $\operatorname{ADC}(2)$ & CC2 & $\mathrm{ADC}(2)$ \\
\hline & $\mathrm{S}_{0} \rightarrow \mathrm{S}_{1}$ & 3.12(10.5) & 3.14(11.4) & $0.22(0.2)$ & $0.33(0.1)$ & $1.08(0.0)$ & $1.15(0.00)$ \\
\hline & $\mathrm{S}_{0} \rightarrow \mathrm{S}_{2}$ & $3.48(0.3)$ & $3.49(0.12)$ & $0.44(8.0)$ & $0.45(7.00)$ & $1.65(0.4)$ & $1.7(0.3)$ \\
\hline & $\mathrm{S}_{0} \rightarrow \mathrm{S}_{3}$ & $3.48(0.3)$ & $3.49(0.12)$ & $1.1(0.0)$ & $1.1(0.00)$ & $1.65(0.4)$ & $1.7(0.3)$ \\
\hline & $\mathrm{S}_{0} \rightarrow \mathrm{S}_{4}$ & $3.64(0.0)$ & $3.65(0.0)$ & $1.57(0.0)$ & $1.62(0.00)$ & $1.98(0.0)$ & $1.92(0.0)$ \\
\hline & $\mathrm{S}_{0} \rightarrow \mathrm{S}_{5}$ & $4.0(0.0)$ & $4.05(0.0)$ & $1.78(0.0)$ & $1.85(0.00)$ & $2.26(0.15)$ & $2.21(0.15)$ \\
\hline & $\mathrm{S}_{0} \rightarrow \mathrm{S}_{6}$ & $4.26(0.3)$ & $4.27(0.2)$ & $1.97(0.2)$ & $2.07(0.20)$ & $2.26(0.15)$ & $2.21(0.15)$ \\
\hline & $\mathrm{S}_{0} \rightarrow \mathrm{S}_{7}$ & $4.26(0.3)$ & $4.27(0.2)$ & $2.12(0.0)$ & $2.22(0.00)$ & $2.64(0.1)$ & $2.59(0.1)$ \\
\hline & $\mathrm{S}_{0} \rightarrow \mathrm{S}_{8}$ & $4.28(0.0)$ & $4.29(0.0)$ & $2.55(0.13)$ & $2.65(0.13)$ & $2.72(0.2)$ & $2.60(0.1)$ \\
\hline & $\begin{array}{c}(\mathrm{nA} / \mathrm{T}) \\
\mathrm{MP} 2\end{array}$ & \multicolumn{2}{|c|}{-3.7} & \multicolumn{2}{|c|}{-50.8} & \multicolumn{2}{|c|}{17.9} \\
\hline
\end{tabular}

\subsubsection{Molecules IV and V}

The lowest VEEs and $\boldsymbol{m}$ values calculated for the neutral and doubly charged $\mathbf{I V}$ and $\mathbf{V}$ species at the ADC(2) level are summarized in the Table 2. For neutral IV and $\mathbf{V}$, we obtained excited states with large $\mathbf{m}$ values at $3.50 \mathrm{eV}$ and $2.88 \mathrm{eV}$, respectively. These transitions provide significant contributions to the paratropic part of the ring current. Due to the large excitation energy, the neutral $\mathbf{V}$ hetero[8]circulene is only weakly antiaromatic and IV with the even larger excitation energy is nonaromatic. For the $\mathbf{I} \mathbf{V}^{2+}$ and $\mathbf{V}^{2+}$ dications, these transitions appear at lower energies of 1.11 and $1.42 \mathrm{eV}$. However, they have though smaller $\mathbf{m}$ values than for neutral $\mathbf{I V}$ and $\mathbf{V}$ (Table 2) leading to a somewhat stronger paratropic ring current of $-4.5 \mathrm{nA} / \mathrm{T}$ and -8.0 nA/T for $\mathbf{I V}^{2+}$ and $\mathbf{V}^{2+}$, respectively. The $\mathbf{I} \mathbf{V}^{2-}$ and $\mathbf{V}^{2-}$ dianions do not have any excited states with a large $\mathbf{m}$ values among the eight lowest excited states. They are therefore aromatic sustaining net diatropic ring currents of $21.7 \mathrm{nA} / \mathrm{T}$ and 15.4 $\mathrm{nA} / \mathrm{T}$ for $\mathbf{I V}^{2-}$ and $\mathbf{V}^{2-}$, respectively.

Table 2. Vertical excitation energies (VEE in $\mathrm{eV}$ ) and the corresponding magnetic dipole transition moments in parenthesis (a.u.) for the neutral and doubly charged IV and V species. The VEEs and transition moments of the states with large magnetic dipole transition moments are highlighted. The MIC strengths (in nA/T) calculated at the MP2 level are also reported.

\begin{tabular}{ccccc}
\hline & & Neutral & Dication & Dianion \\
\hline molecule & Transition & ADC(2) & ADC(2) & ADC(2) \\
\hline IV & $\mathrm{S}_{0} \rightarrow \mathrm{S}_{1}$ & $2.95(0.00)$ & $0.51(0.00)$ & $\mathbf{2 . 0 1 ( 0 . 0 1 )}$ \\
\hline & $\mathrm{S}_{0} \rightarrow \mathrm{S}_{2}$ & $3.35(0.00)$ & $0.51(0.00)$ & $2.04(0.00)$ \\
\hline & $\mathrm{S}_{0} \rightarrow \mathrm{S}_{3}$ & $3.35(0.00)$ & $\mathbf{1 . 1 1 ( 1 . 0 )}$ & $2.04(0.00)$ \\
\hline
\end{tabular}




\begin{tabular}{|c|c|c|c|c|}
\hline & $\mathrm{S}_{0} \rightarrow \mathrm{S}_{4}$ & $3.50(15.8)$ & $1.41(0.00)$ & $2.07(0.00)$ \\
\hline & $\mathrm{S}_{0} \rightarrow \mathrm{S}_{5}$ & $4.62(0.00)$ & $2.43(0.00)$ & $2.38(0.00)$ \\
\hline & $\mathrm{S}_{0} \rightarrow \mathrm{S}_{6}$ & $4.70(0.00)$ & $3.18(0.00)$ & $2.38(0.00)$ \\
\hline & $\mathrm{S}_{0} \rightarrow \mathrm{S}_{7}$ & $4.92(0.00)$ & $3.18(0.00)$ & $2.69(0.00)$ \\
\hline & $\mathrm{S}_{0} \rightarrow \mathrm{S}_{8}$ & $5.04(0.00)$ & $3.43(0.00)$ & $2.79(0.02)$ \\
\hline & $\begin{array}{c}I(\mathrm{nA} / \mathrm{T}) \\
\mathrm{MP} 2\end{array}$ & -0.7 & -4.5 & 21.7 \\
\hline molecule & & Neutral & Dication & Dianion \\
\hline \multirow[t]{10}{*}{ V } & Transition & $\mathrm{ADC}(2)$ & $\operatorname{ADC}(2)$ & $\mathrm{ADC}(2)$ \\
\hline & $\mathrm{S}_{0} \rightarrow \mathrm{S}_{1}$ & $2.88(10.1)$ & $0.29(0.0)$ & $1.19(0.0)$ \\
\hline & $\mathrm{S}_{0} \rightarrow \mathrm{S}_{2}$ & $3.43(0.10)$ & $0.29(0.0)$ & $1.70(0.0)$ \\
\hline & $\mathrm{S}_{0} \rightarrow \mathrm{S}_{3}$ & $3.43(0.1)$ & $0.63(0.2)$ & $1.79(0.3)$ \\
\hline & $\mathrm{S}_{0} \rightarrow \mathrm{S}_{4}$ & $3.50(0.0)$ & $1.40(0.2)$ & $1.79(0.3)$ \\
\hline & $\mathrm{S}_{0} \rightarrow \mathrm{S}_{5}$ & $4.09(0.0)$ & $1.42(8.0)$ & $2.04(0.1)$ \\
\hline & $\mathrm{S}_{0} \rightarrow \mathrm{S}_{6}$ & $4.18(0.0)$ & $1.50(0.2)$ & $2.04(0.1)$ \\
\hline & $\mathrm{S}_{0} \rightarrow \mathrm{S}_{7}$ & $4.29(0.2)$ & $1.62(0.2)$ & $2.44(0.1)$ \\
\hline & $\mathrm{S}_{0} \rightarrow \mathrm{S}_{8}$ & $4.29(0.2)$ & $1.70(0.0)$ & $2.65(0.01)$ \\
\hline & $\begin{array}{c}I(\mathrm{nA} / \mathrm{T}) \\
\mathrm{MP} 2\end{array}$ & -4.0 & -8.0 & 15.4 \\
\hline
\end{tabular}

\subsubsection{Molecules VI and VII}

The lowest ADC(2) excitation energies and magnetic dipole transition moments of the neutral and doubly charged VI and VII species are summarized in the Table 3. The lowest excited state of neutral VI and VII have large $\boldsymbol{m}$ values. The $\mathbf{m}$ value of the lowest excited state of $\mathbf{V I}$ at $3.57 \mathrm{eV}$ is 12.7 a.u. leading to a weakly antiaromatic molecule, whereas neutral VII is more antiaromatic, because the excitation energy of the first excited state is $0.21 \mathrm{eV}$ and it has a relatively large $\boldsymbol{m}$ value of 6.2 a.u. The dications and dianions of VI and VII are aromatic sustaining diatropic ring currents of $4.0-21.9 \mathrm{nA} / \mathrm{T}$.

Table 3. Vertical excitation energies (VEE in $\mathrm{eV}$ ) and the corresponding magnetic dipole electronic transition moments in the parenthesis (a.u.) for compounds VI and VII. VEEs and transition moments for the states with large or significant magnetic dipole transition moments are highlighted. The total MIC strengths (in $\mathrm{nA} / \mathrm{T}$ ) are also reported.

\begin{tabular}{ccccc}
\hline $\begin{array}{c}\text { molecul } \\
\mathrm{e}\end{array}$ & & Neutral & Dication & Dianion \\
\hline VI & Transition & ADC(2) & ADC(2) & ADC(2) \\
\hline & $\mathrm{S}_{0} \rightarrow \mathrm{S}_{1}$ & $\mathbf{3 . 5 7 ( 1 2 . 7 )}$ & $0.40(0.00)$ & $1.28(0.00)$ \\
\hline & $\mathrm{S}_{0} \rightarrow \mathrm{S}_{2}$ & $3.99(0.00)$ & $0.42(0.00)$ & $1.88(0.00)$ \\
\hline & $\mathrm{S}_{0} \rightarrow \mathrm{S}_{3}$ & $3.99(0.00)$ & $0.62(0.00)$ & $1.88(0.00)$ \\
\hline & $\mathrm{S}_{0} \rightarrow \mathrm{S}_{4}$ & $4.11(0.00)$ & $1.63(0.2)$ & $2.20(0.00)$ \\
\hline & $\mathrm{S}_{0} \rightarrow \mathrm{S}_{5}$ & $4.90(0.00)$ & $2.40(0.33)$ & $\mathbf{2 . 2 9 ( 0 . 0 4 )}$ \\
\hline & $\mathrm{S}_{0} \rightarrow \mathrm{S}_{6}$ & $5.02(0.00)$ & $2.57(0.10)$ & $\mathbf{2 . 2 9 ( 0 . 0 4 )}$ \\
\hline & $\mathrm{S}_{0} \rightarrow \mathrm{S}_{7}$ & $5.02(0.00)$ & $2.65(0.00)$ & $2.40(0.00)$ \\
\hline & $\mathrm{S}_{0} \rightarrow \mathrm{S}_{8}$ & $5.56(9.30)$ & $3.41(0.00)$ & $2.77(0.00)$ \\
\hline
\end{tabular}




\begin{tabular}{ccccc}
\hline & $\begin{array}{c}I(\mathrm{nA} / \mathrm{T}) \\
\mathrm{MP} 2\end{array}$ & -2 & 105 & 21.9 \\
\hline VII & & Neutral & Dication & Dianion \\
\hline & transition & ADC(2) & ADC(2) & ADC(2) \\
\hline $\mathrm{S}_{0} \rightarrow \mathrm{S}_{1}$ & $\mathbf{0 . 2 1 ( 6 . 2 )}$ & $1.61(0.01)$ & $0.58(0.0)$ \\
\hline $\mathrm{S}_{0} \rightarrow \mathrm{S}_{2}$ & $0.80(0.04)$ & $1.61(0.01)$ & $0.74(0.0)$ \\
\hline $\mathrm{S}_{0} \rightarrow \mathrm{S}_{3}$ & $1.23(0.13)$ & $1.68(0.001)$ & $0.92(0.0)$ \\
\hline $\mathrm{S}_{0} \rightarrow \mathrm{S}_{4}$ & $1.43(0.1)$ & $2.27(0.1)$ & $\mathbf{1 . 8 2 ( 0 . 3 )}$ \\
\hline $\mathrm{S}_{0} \rightarrow \mathrm{S}_{5}$ & $2.20(0.2)$ & $2.27(0.1)$ & $1.85(0.0)$ \\
\hline $\mathrm{S}_{0} \rightarrow \mathrm{S}_{6}$ & $2.40(0.10)$ & $2.74(1.00)$ & $2.04(0.1)$ \\
\hline $\mathrm{S}_{0} \rightarrow \mathrm{S}_{7}$ & $2.40(0.10)$ & $2.74(1.00)$ & $2.25(0.01)$ \\
\hline $\mathrm{S}_{0} \rightarrow \mathrm{S}_{8}$ & $2.47(1.40)$ & $2.88(0.0)$ & $2.52(0.2)$ \\
\hline$I(\mathrm{nA} / \mathrm{T})$ & -13.2 & 10.5 & 4.0 \\
$\mathrm{MP2}$ & & &
\end{tabular}

\subsection{The molecular orbital analysis}

The molecular structures of the neutral $\mathbf{I}$ and $\mathbf{I V}$ are planar belong to the $\mathrm{D}_{4 \mathrm{~h}}$ point group (see Figure 2). The molecular structures of II, III, V and VI have a lower symmetry than I and VI. They are saddle shaped belonging to the $\mathrm{D}_{2 \mathrm{~d}}$ point group. The molecular structure of VII is also saddle shaped belonging to the less symmetric $\mathrm{C}_{2}$ point group. The dications and dianions of compounds IVII are nonsymmetric belonging to the $C_{1}$ point group. However, since they have approximately the same symmetry as the corresponding neutral molecule, the electronic transitions of the doubly charged species can be labeled in the same way as use for the neutral molecules. The energy diagram of the occupied frontier orbitals (HOMO-n, $\mathrm{n}=0,1, \ldots$ ) and the unoccupied orbitals (LUMO $+\mathrm{n}, \mathrm{n}=0,1, \ldots$ ) that play a significant role in the electronic transitions of the eight lowest excited states of the neutral hetero[8]circulenes I-VII are shown in Figures 4-6. The calculations show the eight lowest excited states are reached by ground-state transitions dominated by $\pi \pi^{*}$ character.

\subsubsection{Molecules I-III}

The transition from HOMO $\left(\mathrm{b}_{2 \mathrm{u}}\right)$ to LUMO $\left(\mathrm{b}_{1 \mathrm{u}}\right)$ of $\mathbf{I}$ dominates the ground-state transition to the $\mathrm{A}_{2 \mathrm{~g}}$ state, which is lowest excited state of neutral I. The HOMO to LUMO transition has a weight of 0.98 leading to a large $\mathbf{m}$ value. For $\mathbf{I}^{2+}$, the strong electronic magnetic dipole transition is the $\mathrm{S}_{0}-\mathrm{S}_{2}$ transition that occurs from the orbital corresponding to HOMO-3 $\left(\mathrm{b}_{1 \mathrm{u}}\right)$ of $\mathbf{I}$ to the one corresponding to HOMO $\left(b_{2 u}\right)$ of $\mathbf{I}$. Here, the frontier orbitals refer to the ones for the neutral molecules. The excitation energies and the transition moments are given in Table 1. The orbital transitions of the neutral molecules are illustrated with red arrows in the orbital energy diagram in Figure 4. The energy gap between HOMO-3 and HOMO of $\mathbf{I}^{2+}$ is much smaller than the energy gap between HOMO and LUMO of $\mathbf{I}$ explaining why the excited state of $\mathbf{I}^{2+}$ with the large $\mathbf{m}$ value lies much lower in energy than the one for $\mathbf{I}$. For $\mathbf{I}^{2-}$, the highest occupied orbital corresponds to LUMO $\left(\mathrm{b}_{1 \mathrm{u}}\right)$ of $\mathbf{I}$. The excitation with a 
large $\mathbf{m}$ value occurs from the highest occupied orbital of $\mathbf{I}^{2-}$ to a higher-lying LUMO of $b_{2 u}$ symmetry. The energy gap between the orbitals is large implying that the first excited state with a large $\mathbf{m}$ value is not found among the first eight electronic transitions. However, the electronic transitions with large $\mathbf{m}$ values are from the orbitals corresponding to LUMO $\left(b_{2 u}\right)$ to LUMO+4, LUMO+5 $\left(\mathrm{e}_{u}\right)$ of neutral $\mathbf{I}$ as indicated by the green arrow in Figure 4.

For II and III, the strong magnetic dipole transition from the $\mathrm{A}_{1}$ ground state to the first excited $\mathrm{A}_{2}$ state is dominated by the transition from HOMO-2 $\left(\mathrm{a}_{2}\right)$ to LUMO $\left(\mathrm{a}_{1}\right)$ and from HOMO $\left(\mathrm{a}_{2}\right)$ to LUMO $\left(\mathrm{a}_{1}\right)$ with weights of 0.97 and 0.90 , respectively. For $\mathbf{I I}^{2+}$, the strong magnetic transition occurs from the orbital corresponding to HOMO-3 $\left(\mathrm{a}_{1}\right)$ to HOMO-2 $\left(\mathrm{a}_{2}\right)$ of II. In the case of $\mathbf{I I}^{2+}$, the first electronic transition does not occur from the orbital corresponding to the HOMO of the neutral molecule II, because the electronic structure optimization of $\mathbf{I I}^{2+}$ affects the relative order of the orbitals. The HOMO (e) of neutral II becomes HOMO-1 of the $\mathbf{I I}^{2+}$ dication.

For III $^{2+}$, the strong magnetic transition occurs from the orbital corresponding to HOMO-3 $\left(\mathrm{a}_{1}\right)$ to HOMO $\left(\mathrm{a}_{2}\right)$ of III. For $\mathbf{I I}^{2-}$ and $\mathbf{I I I}^{2-}$, the LUMO $\left(\mathrm{a}_{1}\right)$ of the neutral molecules is the highest occupied orbital and the lowest $\mathrm{a}_{2}$ orbital lies high up in energy implying that no states of the dianions with a large $\mathbf{m}$ value appear among the eight lowest excited states. For $\mathbf{I I}^{2-}$ and $\mathbf{I I I}^{2-}$, there are electronic transitions with small $\mathbf{m}$ values from the orbitals corresponding to LUMO $\left(\mathrm{a}_{1}\right)$ to LUMO+1, LUMO+2 (e) of II and from the orbitals corresponding to LUMO $\left(\mathrm{a}_{1}\right)$ to LUMO+3, LUMO+4 (e) of III, respectively.
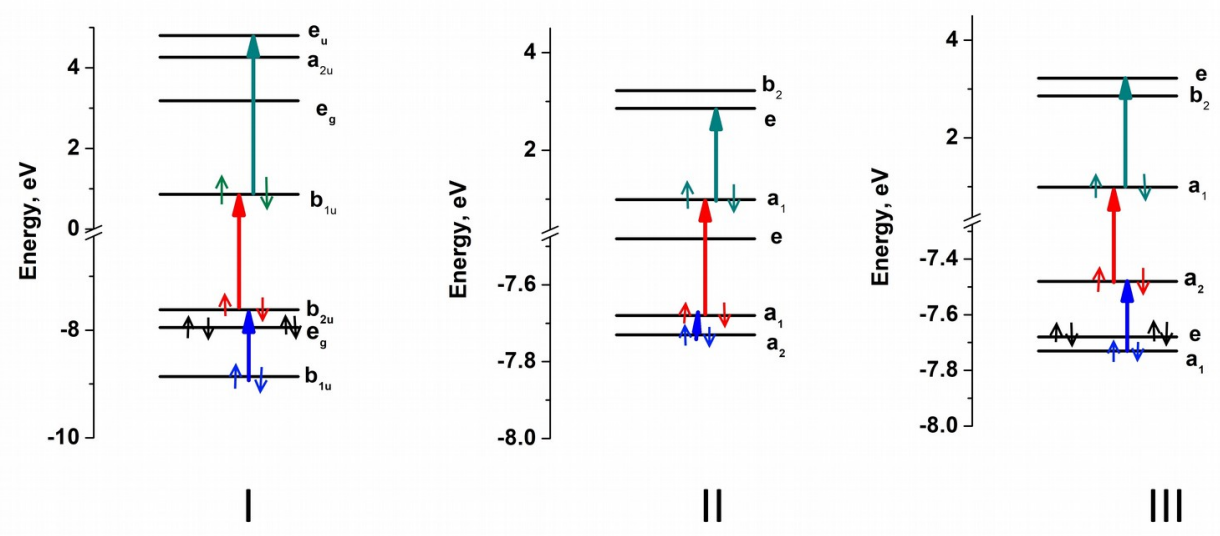

Figure 4. The energy diagram for the frontier molecular orbitals of I-III. The strong magnetic dipole transitions of the practically nonaromatic neutral molecules are shown in red and the corresponding orbital transitions of the strongly antiaromatic diactions are shown in blue. Transitions of the dianions with significant magnetic dipole transition moments are shown in green.

\subsubsection{Molecules IV and V}


For $\mathbf{I V}$, the strong magnetic transition to the $\mathrm{S}_{4}$ state of $\mathrm{A}_{2 g}$ symmetry is completely dominated by the transition from HOMO-2 $\left(b_{2 u}\right)$ to LUMO $\left(b_{1 u}\right)$ with a weight of 0.99 . The magnetic transition to the $\mathrm{A}_{2 g}$ state of $\mathbf{I V} \mathbf{V}^{2+}$ dominates by a transition from the orbital corresponding to HOMO-3 $\left(\mathrm{b}_{2 \mathrm{u}}\right)$ of $\mathbf{I V}$ to the orbital corresponding to LUMO $\left(\mathrm{b}_{1 \mathrm{u}}\right)$ of $\mathbf{I V}$. For $\mathbf{I V}^{2-}$, the weak magnetic transition of the $\mathrm{A}_{2 g}$ state involves electronic transition from LUMO $\left(b_{1 u}\right)$ to LUMO+3 $\left(b_{2 u}\right)$ of IV. The orbital transitions of IV and $\mathbf{I V}^{2+}$ are illustrated with red, blue and green arrows in the orbital energy diagram in Figure 5.

For $\mathbf{V}$, the strong magnetic transition to the $\mathrm{A}_{2}$ state is dominated by a transition from HOMO $\left(a_{2}\right)$ to LUMO $\left(a_{1}\right)$ with a weight of 0.9 . For $\mathbf{V}^{2+}$, the magnetic transition occurs from HOMO-4 $\left(a_{1}\right)$ to HOMO $\left(\mathrm{a}_{2}\right)$ of $\mathbf{V} . \quad \mathbf{V}^{2-}$ is aromatic, because the lowest unoccupied $a_{2}$ orbital lies high in energy relatively to the highest occupied $a_{1}$ orbital and there are only electronic transitions with weak $\mathbf{m}$ from LUMO $\left(a_{1}\right)$ to LUMO+2 and LUMO+3 (e). The orbital transitions are illustrated in Figure 5.

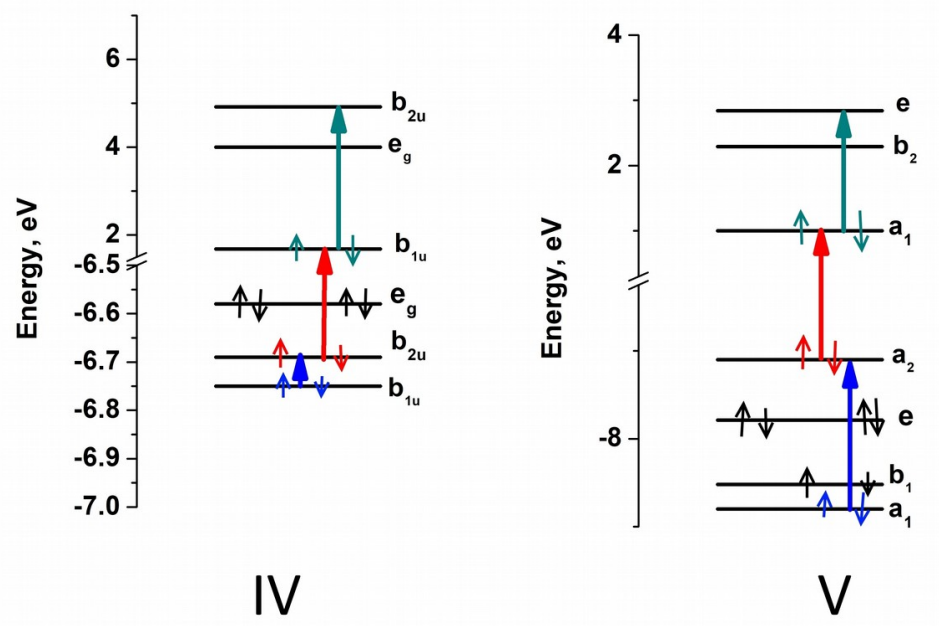

Figure 5. The energy diagram for the frontier molecular orbitals of neutral IV and V. The strong magnetic dipole transitions of the nonaromatic or weakly antiaromatic neutral molecules are shown in red and the corresponding orbital transitions of the antiaromatic diactions are shown in blue. Transitions of the dianions with significant magnetic dipole transition moments are shown in green.

\subsubsection{Molecules VI and VII}

For VI, the strong magnetic transition to the excited state of $A_{2}$ symmetry corresponds to a transition from HOMO $\left(\mathrm{a}_{1}\right)$ to LUMO $\left(\mathrm{a}_{2}\right)$ with a weight of 0.9. For $\mathbf{V I}^{2+}$, the lowest transition with non-vanishing but small magnetic moment $\left(\mathrm{S}_{0} \rightarrow \mathrm{S}_{4}\right)$ involves a transition from HOMO-4 $\left(\mathrm{a}_{2}\right)$ to HOMO $\left(\mathrm{a}_{1}\right)$ of $\mathbf{V I}$. $\mathbf{V I}^{2-}$ has no strong magnetic transition among the eight lowest exited states, because it involves a transition from LUMO $\left(a_{2}\right)$ of VI to a high-lying $a_{1}$ orbital. 
For VII, the most important transition of the strong magnetic moments to the $A$ state is HOMO (b) to LUMO (b) with a weight of 0.8. For $\mathbf{V I I}^{2+}$, the $\mathrm{S}_{0}-\mathrm{S}_{6}$ and $\mathrm{S}_{0}-\mathrm{S}_{7}$ transitions are the lowest transitions with significant but small $\mathbf{m}$ values. They correspond to a transition from HOMO-3 (a) to LUMO (b) of VII. For VII' ${ }^{2-}$, the first eight transitions do not have any large $\boldsymbol{m}$ values. The orbital transitions are illustrated in Figure 6.

The smallest singlet excitation energy of $0.21 \mathrm{eV}$ was calculated at the ADC(2) level for the neutral molecule VII. The multiconfiguration character of the ground state wave function was therefore investigated by performing XMC-QDPT2 calculations, which yielded an excitation energy of $0.17 \mathrm{eV}$ for the lowest triplet state and an excitation energy of $0.39 \mathrm{eV}$ the first singlet state. The weight of the dominating configuration of the ground singlet state is 0.80 indicating that the ground state has some multiconfigurational character, whereas the reasonable agreement between the excitation energies calculated at the XMC-QDPT2 and ADC(2) levels as well as the small $\mathrm{D}_{1}$ diagnostic value of 0.09 suggest that the single-reference methods are appropriate for investigating the aromatic and spectroscopic properties of VII, which seems to be the most problematic molecule among the studied species judged from the small optical gap.
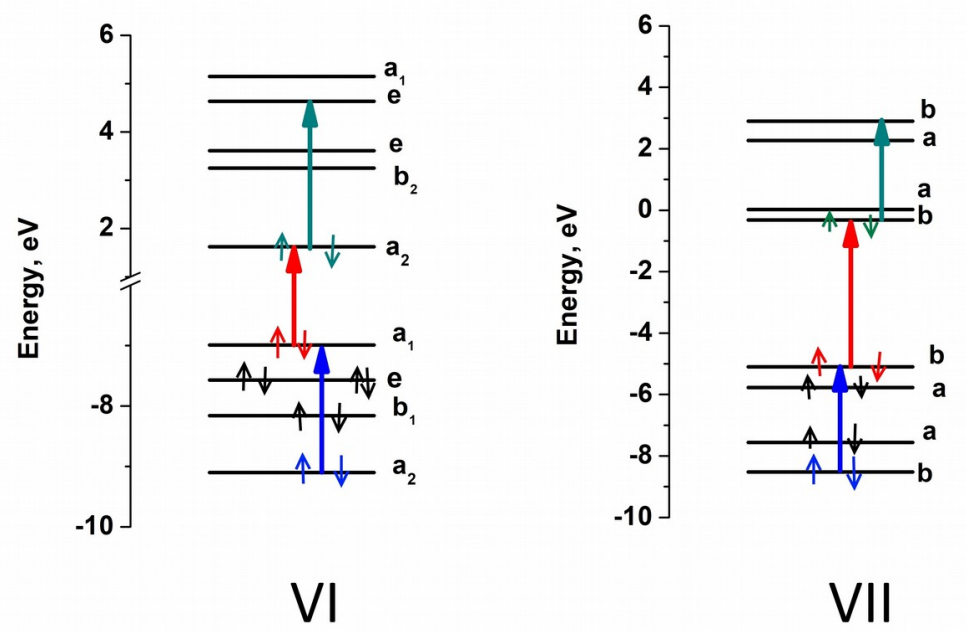

Figure 6. The energy diagram for the frontier molecular orbitals of neutral VI and VII. The strong magnetic dipole transitions of the nonaromatic or weakly antiaromatic neutral molecules are shown in red and the corresponding orbital transitions of the aromatic diactions are shown in blue. Transitions of the dianions with significant magnetic dipole transition moments are shown in green.

\section{SUMMARY AND CONCLUSIONS}

Relations between the aromatic character and spectroscopic properties of the seven hetero[8]circulenes and their double charged ions have been investigated at correlated $a b$ initio levels of theory. The calculations showed that the strongly antiaromatic hetero[8]circulene species have a low-lying exited state with a large magnetic dipole transition moment ( $\boldsymbol{m}$ value). The low-lying excited 
state with a large $\boldsymbol{m}$ value contributes significantly to the paratropic part of the magnetically induced ring-current strength. When the excited state with a large $\boldsymbol{m}$ value lies higher in energy $(\sim 2.8-3.5 \mathrm{eV})$ the molecules is weakly antiaromatic due to the large denominator in the perturbation theory expression in Eq. (1). When the hetero[8]circulene has no excited state below $3.5 \mathrm{eV}$ with a large $\boldsymbol{m}$ value, it is aromatic. Thus, hetero[8]circulenes that have a low-lying excited state with a large magnetic dipole transition moment can be expected to be strongly antiaromatic. This rule may hold more generally, because similar results have previously been obtained for carbaporphyrins and isophlorins [24]. Current density calculations at the MP2 and B3LYP levels lead to the almost same current strengths for weakly antiaromatic and aromatic hetero[8]circulenes, whereas the paratropic ring-current strength of strongly antiaromatic hetero[8]circulenes are overestimated at the B3LYP level.

\section{CONFLICTS OF INTEREST}

There are no conflicts to declare.

\section{ACKNOWLEDGMENTS}

The research was carried out at the expense of the grant from Russian Science Foundation (project No. 17-73-20012). This work was supported by the Academy of Finland through projects 275845 and 297304. Computational resources from CSC - the Finnish IT Center for Science as well as from the Finnish Grid and Cloud Infrastructure (persistent identifier urn:nbn:fi:research-infras2016072533) are acknowledged.

\section{REFERENSES}

[1] G. V. Baryshnikov, B .F. Minaev and V. A. Minaeva, Russ. Chem. Rev., 2015, 84, 455.

[2] T. Hensel, N. N. Andersen, M. Plesner, M. Pittelkow, Synlett, 2016, 27, 498.

[3] N. N. Karaush, G. V. Baryshnikov, V. A. Minaeva, H. Ågren, B. F. Minaev, Mol. Phys., 2017, 115, 2218.

[4] G. V. Baryshnikov, B. F. Minaev, N. N. Karaush and V. A. Minaeva, Phys. Chem. Chem. Phys., 2014, 16, 6555.

[5] S. Akahori, H. Sakai, T. Hasobe, H. Shinokubo and Y. Miyake, Org. Lett., 2018, 20, 304.

[6] C. B. Nielsen, T. Brock-Nannestad, T. K. Reenberg, P. Hammershøj, J. B. Christensen, J. W. Stouwdam and M. Pittelkow, Chem. Eur. J., 2010, 16, 13030.

[7] K. B. Ivaniuk, G. V. Baryshnikov, P. Y. Stakhira, S. K. Pedersen, M. Pittelkow, A. Lazauskas, D. Volyniuk, J. V. Grazulevicius, B. F. Minaev and H. Ågren, J. Mater. Chem. C, 2017, 5, 4123. 
[8] R. R. Valiev, N. N. Karaush, V. A. Minaeva, A. N. Sinelnikov, S. K. Pedersen, M. Pittelkow, B. F. Minaev and H. Ågren, Phys. Chem. Chem. Phys., 2016, 18, 28040.

[9] T. Fujimoto, M. M. Matsushita and K. Awaga, Appl. Phys. Lett., 2010, 97, 123303.

[10] T. Fujimoto, M. M.Matsushita and K. Awaga, Chem. Phys. Lett., 2009, 483, 81.

[11] A. Dadvand, F. Cicoira, K. Yu. Chernichenko, E. S. Balenkova, R. M. Osuna, F. Rosei, V. G. Nenajdenko and D. F. Perepichka, Chem. Commun., 2008, 5351.

[12] G. V. Baryshnikov, R. R. Valiev, B. F. Minaev and H. Ågren, New J. Chem., 2017, 41, 2717.

[13] G. V. Baryshnikov, R. R. Valiev, N. N. Karaush and B. F. Minaev, Phys. Chem. Chem. Phys., 2014, 16, 15367.

[14] G. V. Baryshnikov, R. R. Valiev, N. N. Karaush, D. Sundholm and B. Minaev, Phys. Chem. Chem. Phys., 2016, 18, 8980.

[15] G. V. Baryshnikov, N. N. Karaush, R. R. Valiev and B. F. Minaev, J. Mol. Model., 2015, 21, 136.

[16] S. Radenković, I. Gutman, P. Bultinck, J. Phys. Chem. A, 2012, 116, 9421.

[17] S. Coriani, P. Lazzeretti, M. Malagoli and R. Zanasi, R. Theor. Chim. Acta, 89, 1994, 181.

[18] E. Kleinpeter, A. Koch, S. Schulz and P. Wacker, Tetrahedron, 2014, 70, 9230.

[19] S. Klod and E. J. Kleinpeter, Chem. Soc. Perkin Trans., 2, 2001, 1893.

[20] Z. Chen, C. S. Wannere, C. Corminboeuf, R. Puchta and P. v R. Schleyer, Chem. Rev., 2005, 105, 3842.

[21] T. Nishinaga, T. Ohmae and M. Iyoda, Symmetry, 2010, 2, 76.

[22] V. T. T. Huong, T. B. Tai and M. T. Nguyen, RSC Adv., 2015, 5, 24167.

[23] R. R. Valiev, H. Fliegl and D. Sundholm, Chem. Commun., 2017, 53, 9866.

[24] R. R. Valiev, H. Fliegl and D. Sundholm, Phys. Chem. Chem. Phys., 2017, 19, 25979.

[25] R. R. Valiev, I. Benkyi, Y. V. Konyshev, H. Fliegl and D. Sundholm, J. Phys. Chem. A, 2018, 122, 4756.

[26] W. Kohn and L. J. Sham, Phys. Rev., 1965, 140, A1133.

[27] A. D. Becke, J. Chem. Phys., 1993, 98, 5648.

[28] C. Lee, W. Yang and R. G. Parr, Phys. Rev. B: Condens. Matter Mater. Phys., 1988, 37, 785.

[29] F. Weigend and R. Ahlrichs, Phys. Chem. Chem. Phys., 2005, 7, 3297.

[30] J. Schirmer, Phys. Rev. A, 1982, 26, 2395.

[31] A. B. Trofimov and J. Schirmer, J. Phys. B, 1995, 28, 2299.

[32] C. Hättig, Adv. Quantum. Chem., 2005, 50, 37.

[33] TURBOMOLE V7.2 2017, a development of University of Karlsruhe and Forschungszentrum Karlsruhe GmbH, 1989-2007, TURBOMOLE GmbH, since 2007; available from http://www.turbomole.com. 
[34] F. Furche, R. Ahlrichs, C. Hättig, W. Klopper, M. Sierka, and F. Weigend, WIREs Comput. Mol. Sci., 2014, 4, 91.

[35] A. A. Granovsky, J. Chem. Phys., 2011, 134, 214113.

[36] A. A. Granovsky, Firefly version 8.0.0, www http://classic.chem.msu.su/gran/firefly/index.html.

[37] H. Fliegl, R. R. Valiev, F. Pichierri and D. Sundholm, Chem. Model., 2018, 14, 1.

[38] D. Sundholm, H. Fliegl and R. J. F. Berger, WIREs Comput. Mol. Sci., 2016, 6, 639.

[39] H. Fliegl and D. Sundholm, J. Org. Chem., 2012, 77, 3408.

[40] J. Jusélius, J. Gauss and D. Sundholm, J. Chem. Phys., 2004, 121, 3952.

[41] H. Fliegl, S. Taubert, O. Lehtonen and D. Sundholm, Phys. Chem. Chem. Phys., 2011, 13, 20500.

[42] M. Kollwitz and J. Gauss, Chem. Phys. Lett., 1996, 260, 639.

[43] P. Lazzeretti, Prog. Nucl. Magn. Reson. Spectrosc., 2000, 36, 1.

[44] E. Steiner and P. W. Fowler, Phys. Chem. Chem. Phys., 2004, 6, 261. 